\title{
Food crisis: how to define it statistically?
}

\author{
C. L. Lee, M. H. Lee \& J. H. Lee \\ Department of Economics, Korea University at Sejong, Korea
}

\begin{abstract}
Climate change may affect food production and ultimately result in a food crisis. But, what phenomena does a food crisis involve and how serious must the food shortage be to qualify as a 'crisis'? To answer this, we attempt to 'define' a food crisis by applying standard microeconomic approaches and examine the history of past food crises. We first build three indices that measure the degree of food crisis, i.e., nonlinear trend deviation index, food shortage index, and food market index. Basically, each index represents a variant measure of the food market's supply shortage and/or price increase. We then use data of 182 countries from 1961 to 2009 to estimate each index and attempt to identify the occurrence of food crises for each country. All three indices indicate that two major food crises occurred in 1973 and 2008 on a global scale, while minor ones took place less uniformly for different years for different countries during the sample period. The food shortage index seems more reliable than the other two by identifying the outbreaks of food crisis more systematically. Keywords: food crisis, food shortage index, food price, food production.
\end{abstract}

\section{Introduction}

A food crisis is regarded as a situation when food security is abruptly threatened. Despite this general definition, it is not easy to do it by applying the statistical data because the existing definitions of food crisis are only conceptual. For example, we may encounter a very fundamental problem on these researches such as how they identify those periods as periods of food crisis.

There are many researches in the food crisis. They analyse the causes of food crisis and usually explain how to prevent it. For example, Headey et al. [2] examine the food crisis from 2000 to 2009 and show the major reasons for food crisis and emphasize the impacts of food crisis. Other examples are Schnittker [3], Golay [4] and Park [5]. They argue that the food crises had 
happened globally in 1973 to 1974, 1980, and 2008 and showed that several supply and demand factors such as global abnormal climate or the increase in production cost caused by the oil shocks as well as some political factors.

Despite these all arguments, we may encounter a very fundamental problem on these researches because they do not identify those crises from any objective and statistical ways. They simple assume that food crisis happen at a certain year and then analyse them.

This paper is an attempt to solve such problems. We try to define the food crisis in a more scientific way based on the statistical data and economic theory and to examine the food crisis of the countries around the world. We formulate the excess demand of the food market and define the crisis where the excess demand reached the certain level. This approach is not new in Economics. Rather it is very well known in the literature on the financial crisis such as Eichengreen et al. [1] or Frankel and Rose [6].

This study consists of the following: The first section is an introduction and the second one is the theoretical parts of the study. We introduce three definitions of food shortage indices and give a definition of a food crisis based upon these indices. We also show the estimation methods to identify the food crisis and explain data used in this paper. The third section identifies the food crisis based upon by the definition and estimation methods introduced in the previous section. Finally, the last section summarizes the study and suggests a few policy implications.

\section{Methodology}

\subsection{Non-linear Trend Deviation Index (NTDI)}

Following Araujo et al. [7], we define a food crisis when a food price or production reaches over a certain critical level. To determine the certain critical level for the food crisis, we estimate a trend equation representing the past trend of food price or production quantity and derive a prediction error of each period. Then we define the ratio of prediction error over its standard error as a trend deviation index. And finally we identify the food crisis as a time period when the trend deviation index reaches a certain level. It is called as Linear Trend Deviation Methodology (LTDM) which was used to identify the food crisis of sub-Saharan economies of Burkina, Niger, Mali in Africa from 1990 to 2008. We identify the food crisis as the time period when the deviation index is greater than 1.96. The one of the reasons for choosing such a critical level is that we like utilize a simple normal distribution theory in Statistics.

\subsection{Food Shortage Index (FSI)}

The second methodology used to identify the food crisis is to build up the Food Shortage Index (FSI) which represents the shortage or excess demand of the food market. It was originally developed by Eichengreen et al. [1] who estimates the excess demand of foreign exchange market to identify the currency crisis. 
We apply food price and production to define a food shortage index as in the below equation

$$
\text { FSI }_{t}=\omega_{1} \times \Delta \text { Price }_{t}+\omega_{2} \times \Delta\left(- \text { Production }_{t}\right)
$$

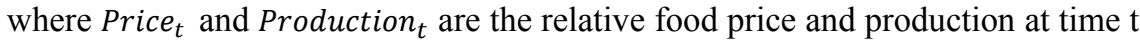
and $\omega_{i}$ is the weight (standard deviation) of either price or quantity. The relative food price means the ratio of food price over the other good and service prices. Consequently, FSI estimates the shortage of the food market by a weighted average of the price and quantity change. This study estimate FSI of each country and identify its food crisis as FSI reaches at the certain level.

We classify the food crisis by three levels such as the level 1 food crisis, the level 2 food crisis and the level 3 food crisis. The level 1 food crisis means a moderate food crisis, while the level 2 food crisis and the level 3 food crisis means a serious one and an extremely serious one, respectively. Statistically we define the level 1 food crisis as the one when its critical value is the one at the 85 percent confidence interval of FSI. By same principle, the level 2 and the level 3 crisis are defined as the ones when the critical values of 90 percent and 95 percent of confidence of FSI are applied, respectively.

\subsection{Food Market Indicator (FMI)}

The last method used to identify the food crisis was the Food Market Indicator (FMI) which applying Frankel and Rose's indicators used in the foreign exchange market. The Food Market Indicator (FMI) is either the relative food price index or food production index per capita and the food crisis is identified as the time periods when FMI sharply changes. We classify the food crisis by three levels such as the level 1 food crisis, the level 2 food crisis and the level 3 food crisis as in the case of food crisis classified by food shortage index The level 1 food crisis means a moderate food crisis where the level 2 and the level 3 food crisis do a serious one and an extremely serious one, respectively.

When we apply the food price to identify the food crisis, the critical levels are set up as the case when the price rises by more than 5 percents, 7.5 percents and 10 percents. When only applying only food production, they are set as when food production falls by more than 10 percents, 20 percents and 50 Percents.

\subsection{Data}

To estimate the above indices, we apply the data of many countries from many different sources. First, we take the price data of OECD [8], South Korea [9] and Malaysia [10] from 1960 to 2010 from their statistical offices. Second, when the price level excluding food price are available, we take them to get the relative food price. But if not as in the cases of Russia, Brazil, China, Indonesia and Malaysia, we simple use the CPI as the food-excluding price level of each country. Third, we use the food production data form from FAO [11,12] and IMF [13] from 1961 to 2009. FAO provides value of food production of each country, so that we have to make food production level by dividing it by the world food price from IMF. 
Table 1: $\quad$ Country-specific food crises based on price-centric NTDI.

\begin{tabular}{|c|c|}
\hline Country & Period \\
\hline US & 1974 \\
\hline CANADA & $1979-81$ \\
\hline ISRAEL & 1980,1986 \\
\hline
\end{tabular}

Note: the sample countries are 23 countries from 1960 to 2010.

\section{Empirical results of food shortage indices}

When we apply the NTDI method to the food price of 23 countries and identify the year when the prediction error of the relative price over its standard deviation is bigger than the critical level. Figure 1 and Table 2 present the estimation results indicating that 6 food crises occurs in 3 countries out of 23 countries which related data are available from 1960 to 2010. In detail, we find that the food crises happened in United States in early to mid-1970s as indicated by Schnittker [3].

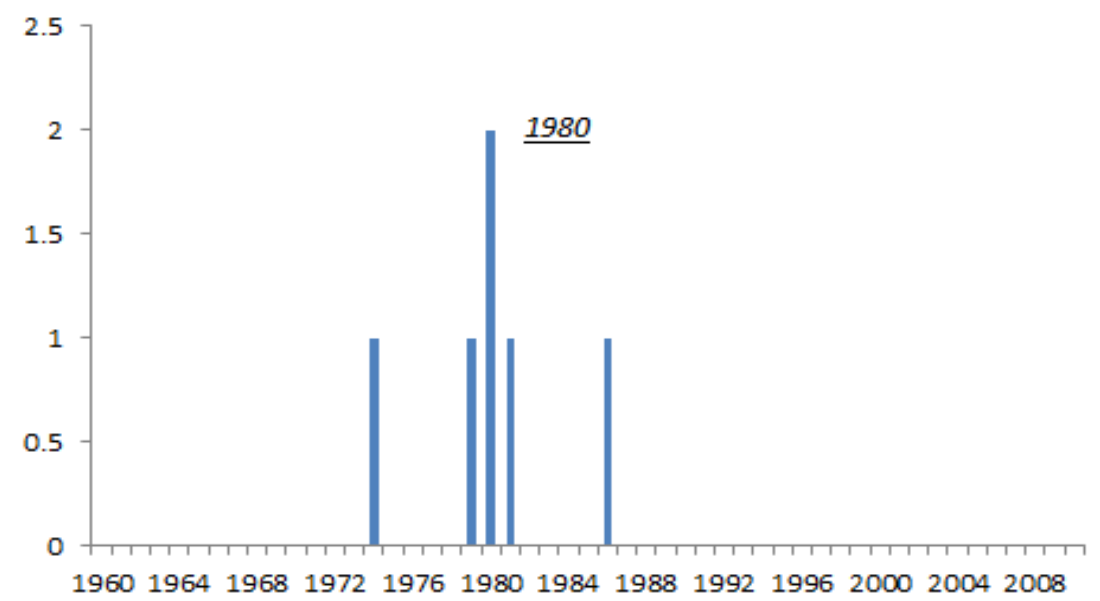

Note: the sample countries are 23 countries from 1960 to 2010.

Figure 1: $\quad$ Food crises based on price-centric NTDI.

Second, we apply the NTDI method to the food production for 182 countries from 1961 to 2009 and identify the year when the prediction error of the food production over its standard deviation is bigger than 1.96. The results are shown in figure 2 and table 3 . In detail, the food crises had occurred 17 times in 21 countries among 182 from 1961 to 2009. The crises mostly occurred in 1973-4 as Schnittker [3] suggested. Third, the Food Shortage Index (FSI) was estimated applying the data of 40 countries from 1961 to 2010 to identify the food crisis in 
Table 2: $\quad$ Country-specific food crises based on production-centric NTDI.

\begin{tabular}{|l|c||l|c|}
\hline \multicolumn{1}{|c|}{ Country } & Period & \multicolumn{1}{c|}{ Country } & Period \\
\hline \hline Armenia & 2008 & Korea & 1974 \\
\hline \hline Bahrain & 1974 & Romania & 1974 \\
\hline \hline Bulgaria & 1974 & Saint Kitts and Nevis & 1974 \\
\hline \hline Dominica & 1980 & $\begin{array}{l}\text { Saint Vincent and the } \\
\text { Grenadines }\end{array}$ & 1974 \\
\hline \hline Hungary & 1974 & Saudi Arabia & 1979,1980 \\
\hline \hline Ireland & 1974 & Suriname & 1973,1974 \\
\hline \hline Kuwait & 1991 & Syria & 1973 \\
\hline \hline Malaysia & 2008 & Thailand & 1974 \\
\hline \hline Netherlands & 1974 & United Kingdom & 1974 \\
\hline \hline Oman & 1974 & & \\
\hline \hline
\end{tabular}

Note: the sample countries are 23 countries from 1960 to 2010.

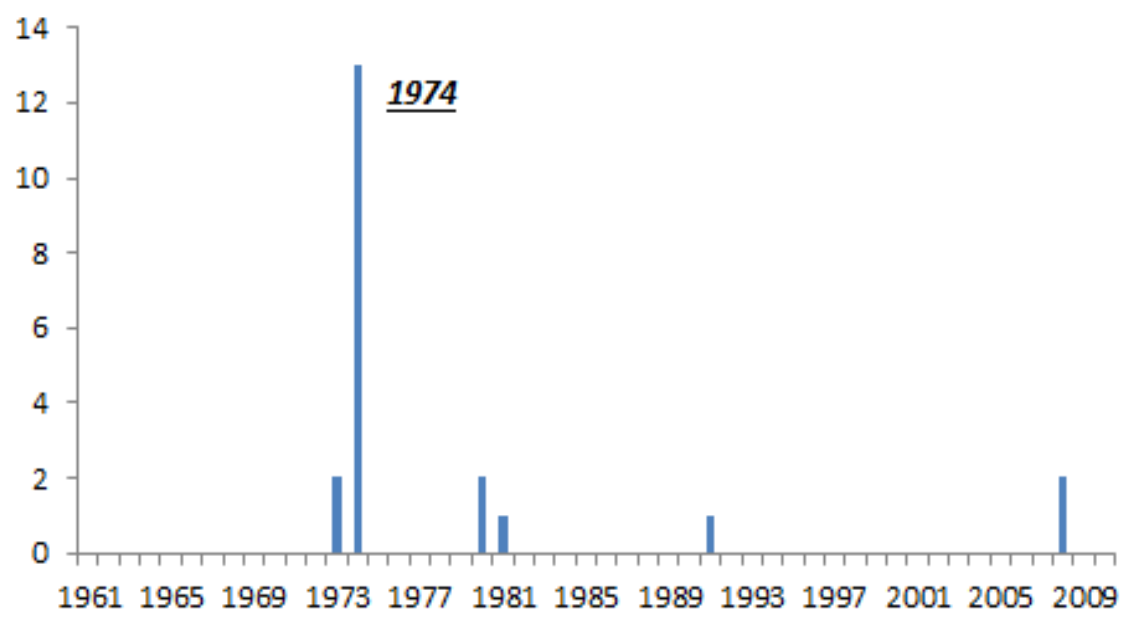

Note: the sample countries are 182 countries from 1960 to 2010.

Figure 2: $\quad$ Food crises based on production-centric NTDI.

the world. According to Figure 3, we find that level 1 food crises has happened 58 times in 30 countries among the sample of 40 countries from 1961 to 2009 and level 2 one has 35 times in 27 countries. And finally, level 3 one occurs in 19 times in 18 countries. Two countries experience level 3 crisis in 2008 while 15 countries did in 1973. 
Table 3: $\quad$ Regional food crises on production-centric FMI.

\begin{tabular}{|c|c|c|c|c|c|c|c|}
\hline \multirow{2}{*}{ Type } & \multirow{2}{*}{$\begin{array}{c}\text { Total } \\
(214)\end{array}$} & $\begin{array}{c}\text { Asia } \\
(47)\end{array}$ & $\begin{array}{c}\text { Europe } \\
(49)\end{array}$ & $\begin{array}{c}\text { Africa } \\
(53)\end{array}$ & $\begin{array}{c}\text { Oceania } \\
(20)\end{array}$ & $\begin{array}{c}\text { South } \\
\text { America } \\
(21)\end{array}$ & $\begin{array}{c}\text { North } \\
\text { America } \\
(24)\end{array}$ \\
\hline \multirow{4}{*}{ Level 1 } & 1,671 & 407 & 303 & 548 & 91 & 176 & 146 \\
& $(180)$, & $(44)$ & $(43)$ & $(50)$ & $(9)$ & $(18)$ & $(16)$ \\
& {$[9.28]$} & {$[9.25]$} & {$[7.05]$} & {$[10.96]$} & {$[10.11]$} & {$[9.78]$} & {$[9.13]$} \\
\hline \multirow{3}{*}{ Level 2 } & 455 & 131 & 55 & 164 & 27 & 34 & 44 \\
& $(165)$, & $(40)$ & $(34)$ & $(49)$ & $(8)$ & $(18)$ & $(16)$ \\
& {$[2.76]$} & {$[3.28]$} & {$[1.62]$} & {$[3.35]$} & {$[3.38]$} & {$[1.89]$} & {$[2.75]$} \\
\hline \multirow{3}{*}{ Level 3 } & 208 & 59 & 33 & 68 & 9 & 22 & 17 \\
& $(155)$, & $(38)$ & $(28)$ & $(48)$ & $(8)$ & $(18)$ & $(15)$ \\
& {$[1.34]$} & {$[1.55]$} & {$[1.18]$} & {$[1.42]$} & {$[1.13]$} & {$[1.22]$} & {$[1.13]$} \\
\hline
\end{tabular}

Notes: Level 1, Level 2, Level 3 denotes the diminution of food by ' $10 \%$ ', ' $20 \%$ ', and ' $50 \%$ ' respectively. '( )' and '[ ]' are the number of country and food crises per country respectively.

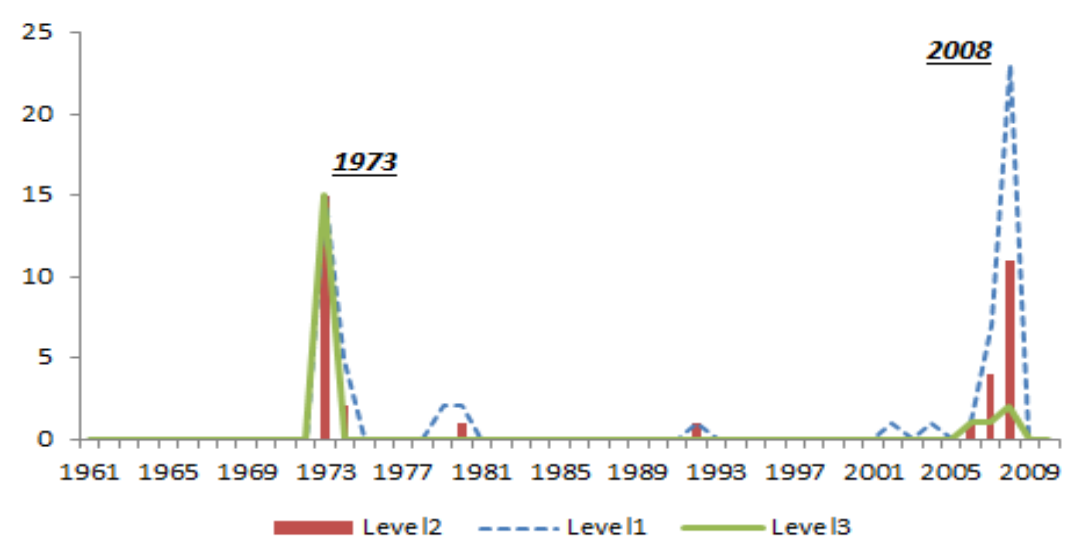

Figure 3: $\quad$ Food crises based on FSI.

Fourth, we identify the food crisis based on FMI only including the fluctuation of the relative price of the food and show the result in Figure 4. As suggested in section 2, we classified the crisis into three levels such as 'Level 1 price rise (moderate), 'Level 2 price rise (serious)', and 'Level 3 crisis' (extremely serious) according to size of the rise of the relative price by ' $2.5 \%$ ', ' $5 \%$ ', and ' $7.5 \%$ ', respectively. 


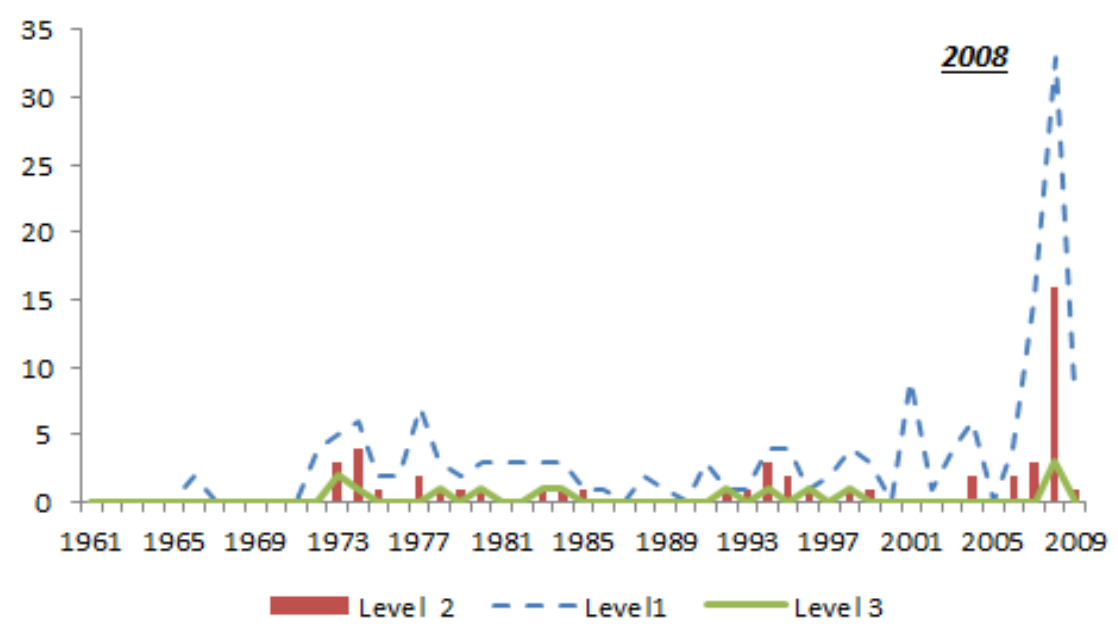

Figure 4: $\quad$ Food crises based on price-centric FMI.

From 1961 to 2009, 'Level 1 price rise' occurs 150 times in 39 countries among 40 countries, while 'Level 2 price rise' does 50 times in 29 countries and 'Level 3 price rise of crisis' does 14 times in 9 countries. It says that there happened many 'somewhat serious' food crises from 1960 to the present while the 'extremely serious' crises were comparatively rare. In addition, it indicated that seven countries experienced food crises in 1973-4 and most of them occurred in major food exporting countries such as Canada and the United States. It shows that the food crisis occurs in 16 countries in 2008 and most of them are food importing countries.

Fifth, we apply the FMI to detect the food price but only taking care of the food production of the each country. As in the fourth method, we classify the food crisis into 'Level 1(moderate production decrease)', 'Level 2(serious production decrease)', and 'Level 3(extremely serious crisis)' according to degree of reduction by ' $10 \%$ ', ' $20 \%$ ', and ' $30 \%$ ' respectively. As shown in Figure 5, 'Level 1' production downturns occurred 1671 times in 180 countries while 'Level 2' serious downturns occurred 455 times in 165 countries. 'Level 3 production reduction of crisis occurs 208 times in 155 countries. By looking at the production reduction by period, the 'Level 1' production reduction arose very frequently. For example, the crises extensively happened in very many countries through 1973, 1980, 1986, 2004, and 2008. Considerably many countries experienced 'Level 2' production reduction especially in 1973 and 2008. Meanwhile, it is shown that 'Level 3' crisis occur many time including 1973, 2000 and 2001 but it did not in 2008. 


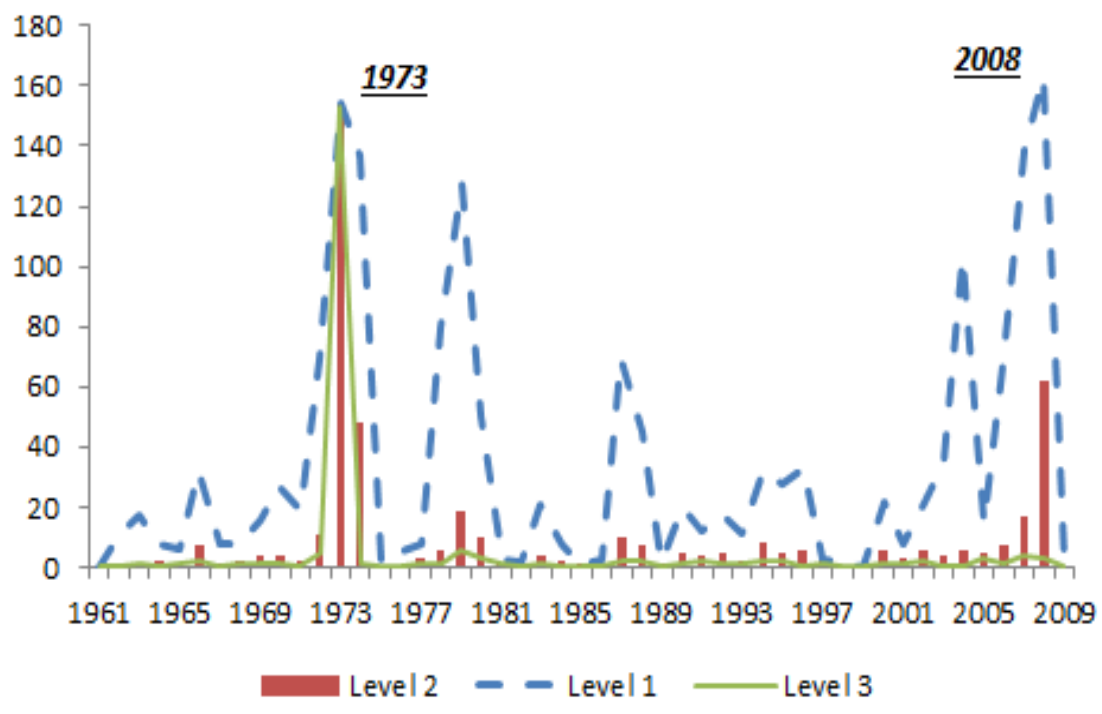

Figure 5: $\quad$ Food crises based on production-centric FMI.

The food production quantity is considered to have a close relationship with the country's regional climate. Thus, the results are sorted by six continents and the differences are examined. As stated in Table 3, the European continent, where developed countries are relatively concentrated, has the lowest occurrence in general, compared to other continents. 'Level 1' and 'Level 2' food crises are more frequent in Africa, Oceania, and North America compared to Asia or Europe. 'Level 3' extreme crises mostly occur in South America while Europe and North America have a relatively lower occurrence rate.

As mentioned above, all five methodologies present slightly different results of the food crisis but considering the previous studies by Schnittker [3] and Park [5], the world has experienced two huge crises (in 1973-4 and 2008) from 1961 to 2009. Furthermore, the FSI methodology appeared to be the best explanation of these circumstances, but FMI, which is determined by relative price and abrupt decline of production, can be utilized as an assistant indicator of FMI. Thus, FMI shows that the crisis in 1973 was mainly caused by the rapid decline of production rather than the price upsurge whereas the crisis in 2008 was primarily induced by the price rise. On the other hand, NTDI has limits in explaining the past global food crises.

\section{Concluding remarks}

This paper attempts to define the food crisis based on the simple economics theory such as the abrupt price upsurge, the sharp production decline, or the combination of these two. According to the results from the analyses based on nonlinear trend deviation index, food supply shortage index, and food market 
index from the definition, the world experienced huge food crises in 1973 and in 2008 range as Schnittker [3], Park [5] Golay [4] or Headey et al. [2] suggest. Among the several methodologies, the result measured by the food shortage index from the ERW abrupt price upsurge, the sharp production decline, or the combination of these two as well.

We find several important facts as follows. First, many countries experience food crisis for the past three decades. Almost every country does at least ones the light or moderate food crisis in past 50 years.

Second, food crisis occur in several countries at the same time. Especially, we find the several countries experiences food crisis in 1973, 1980 and 2008.

Third, the crisis occurs mainly in Asia and Africa which are composed of low income developing countries. We find that Western Europe or North America have less food crisis than any other regions.

From this study, we realize the importance of an international cooperation or the role of international organization to prevent food crisis. We find that the food crises in 1973 and 2008 turn out to be not restricted into some individual countries but extended into globally. Once the food crisis is extended in global world, it should be solved only by international cooperation.

Furthermore, the food crisis more frequently occurred in low income countries which were not able to approach the international food market.

\section{References}

[1] Eichengreen, B., A. K., Rose and C. Wyplosz, "Exchange Market Mayhem: the Antecedents and Aftermath of Speculative Attacks," Economic Policy, 1995, pp. 251-395.

[2] Headey, Derek and Shenggen Fan, Reflections on the Global Food Crisis, Research Monograph 165, International food Policy Research Institute, 2010.

[3] Schnittker, J. A., "The 1972-73 Food Price Spiral," Brookings Papers on Economic Activity, Vol. 2, 1973.

[4] Golay, Christophe, The Food Crisis and Food Security: Towards a New World Food Order?, International Development Series 2010-1, 2010.

[5] Park, W. I., The Strategy of New Food Security in the Food Crisis Age, Samsung Economic Research Institute, Working Paper, 2011. 2. 14.(Korean).

[6] Frankel, J. and A. K., Rose, "Currency Crashes in Emerging Markets: An Empirical Treatment," Journal of International Economics, Vol. 41, 1996, pp. 351-366.

[7] Araujo C., C. A. Bonjean and S. Brunelin, "Alert at Maradi: Preventing Food Crisis using Price Signals,” Etudes et Documents, CERDI, 2010.

[8] OECD, Organization for Economic Cooperation and Development, http://www.oecd.org

[9] Statistics Korea, Korean Statistical Information Service, http://www.kosis.kr

[10] Department of Statistics, Malaysia, http://www.statistics.gov.my 
312 Environmental Impact

[11] FAO, www.fao.org

[12] FAO, Crop Prospects and Food Situation, April, 2008.

[13] IMF, International Financial Statistics, various issues. 